DOI: https://doi.org/10.47405/mjssh.v6i3.711

\begin{tabular}{|c|c|}
\hline 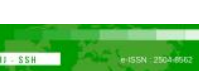 & Malaysian Journal of Social Sciences and Humanities (MJSSH) \\
\hline $\begin{array}{l}\text { Malaysian Journal of } \\
\text { socail sciences and }\end{array}$ & Volume 6, Issue 3, March 2021 \\
\hline $\begin{array}{l}\text { Humantes } \\
\text { (MJ-SSH) }\end{array}$ & e-ISSN : 2504-8562 \\
\hline & $\begin{array}{l}\text { Journal home page: } \\
\text { www.msocialsciences.com }\end{array}$ \\
\hline
\end{tabular}

\title{
A Study on The Impact of Government Using Social Media as Medium in Sharing Information to Public
}

\author{
Izzat Bin Basiran1, Masri Bin Abdul Lasi' \\ ${ }^{1}$ City Graduate School, City University Malaysia \\ 2Faculty of Business, City University Malaysia \\ Correspondence: Izzat Bin Basiran (izzatbsrn@gmail.com)
}

\begin{abstract}
Several Studies shows that the used of social media as flatform of communication. The wide use of social media has changed the value of the information and individual role. Social media has been a great platform for knowledge sharing and even getting better as medium of communication and collaboration. The study aimed to examine the Impact of Government Using Social Media as Medium in Sharing Information to Public. The independent variables (Value, Role, Membership, Knowledge Sharing and Collaboration \& Intention) of this study were used as primary goals of this research, while the dependent variable is Used of Social Media. The impacts that the users received from the new method, which is the social media that open the opportunity for people to gain tremendous knowledge not only on the past stories where it has become history, but also the current news which is latest and in a real-time basis story and news. The data collected from the quantitative study were distributed to the public in Kuala Lumpur via questionnaires to 150 respondents, since the researchers assume that Kuala Lumpur has a high population density from various population groups. Statically Package for Social Science (SPSS) were used to analyze the correlation and determining the validity of the hypotheses. This study found that people are not really being impacted from the information shared from government agencies. It is recommended for future researcher to study the link between social media as a medium in sharing information with the aspect that impacted in people daily life and the role of government in controlling the news and information.
\end{abstract}

Keywords: social media use, role, value, membership, knowledge sharing, collaboration and interaction

\section{Introduction}

Social Media (Socmed) have widely been used and now have become an important part of public discourse and communication in the $21^{\text {st }}$ century society. The influence of social media has been an entertaining complement to being a fully integral part of virtually every aspect of everyday life (Wharton 2019). The increase amount of usage of social media gives a big impact not only in individual life but also the society as it has created new norm where people living with information in their fingertips (SimpliLearn, 2020). This is because social media has been used in many aspects of our life and it has influenced our lifestyle. 
Wharton (2019) has defined that the influence of the social media has been an entertaining contribution to virtually every area of everyday life that has been thoroughly incorporated for many awareness. The wide use of social media has changed the value of the information and individual role. Membership of social media page getting higher. Social media has been a great platform for knowledge sharing and even getting better as medium of communication and collaboration.

In addition, social media provided online platforms to facilitate multimedia content sharing. For instance, social media has been proven to be use in higher education system. It is in needed, so student can cope with their study in this modern era (Shaharudin, 2018). Make it easier for them to do further research or interacting between their colleague or lecturers. It will be required fewer physical activities as the information can be obtain by using only the fingertips.

Government agencies have also benefited from the use of social media. In the attempts to resolve the public interest in more access to information, systemic accountability, participatory decision-making and public service access, policymakers are starting to use the Internet of Things (IoT), and associated area of information and communication (ICT). (Tursunbayeva, Franco, \& Pagliari, 2017). It is shown that social media have become an integral part of public.

Sophisticated of technology have created a smartphone. It is actually a mobile phone with ability of supercomputer. This existence has created a new social media. A new social media appears with an application that can be access anytime and anywhere by only using fingertips as long it has an internet connection. Facebook, Twitter, Instagram and YouTube are a few lists of most popular social media platform (Hogan \& Strasburger, 2018). The barrier for communication has been break. The information now can be sharing in the ways more effective with the fancy and catchy so the target audience easy to understand.

The social media environment has two aspects: (1) networks to include enterprise and ecosystem technology and business models and (2) use scenarios, such as how different categories of individual and company use these technologies. (Appel, Grewal, Hadi, \& Stephen, 2019). As per context of this study, government agency uses the technology as a platform that provide information and business models to guide and govern the public. It is being done by using Social media distribute the general idea, overview, and guideline of the process.

The trend of information-seeking has shifted from using newspaper, magazine, and libraries to new method by adopting advanced technologies such as website or search engines and now to the social media (Bukhari, Hamid, Ravana, \& Ijab, 2018). It can be said that nowadays, information is accessible by everyone, no one is excluded. People can get to know any news regarding any topic they desire.

As for example, we are now able to know the current issues arise all around the world only by using the social media. The used of newspaper or poster to distribute an information are gradually decrease. Even the newspaper's companies are changing their approach to reach people by utilizing the internet to the fullest. It is proven that even social media sites have surpassed print newspapers as a news sources for Americans (Shearer, 2018) at the Uncle Sam country.

The impacts that the users received from the new method, which is the social media that open the opportunity for people to gain tremendous knowledge not only on the past stories where it has become history, but also the current news which is latest and in a real-time basis story and news. It is found that knowledge sharing, creativity, collaboration and interaction through social media have a significant impact in higher educational institution (Khan, Ahmed, Din, \& Amin, 2017). Students get to be more creative by looking for the idea and inspiration from the social media. The number of young talents increase like mushrooms after a rain.

This study focuses on one of the corporate and company governing bodies. One of its functions is that of serving as an agent for corporations and registering businesses. It also serves as the government's agent in managing and delivering services, ensuring the provision of the Companies Commission of Malaysia act and laws are applied and followed and controlling corporate, company and corporate 
relations with respect to the laws that are administered. Since using social media, this study would like to examine what it impacts, how and why the consumers.

\section{Literature Review}

\section{Value and Used of Social Media as Medium in Sharing Information to Public}

The advancement of technologies has provided a better platform for individual or an organization to share their content. Everyone can create their own contents and shared it to public. This has created a world without an obvious boundary. There is no longer needed to go to the library to look for certain information. The technologies have reduced the paper consume where the new platform is now on digital site. It is a great chance for people to use. They can exploit the benefit by spread the good news or bring awareness easier. Cost incurred will be reduce as there is no more need for paper consumptions, marker or any other stationeries due to the social media abilities to reach thousands of people without the need of big gathering event and physical campaign. It is all through virtual campaign on social media.

Therefore, there is a close opinion that social media marketing is important because it enables businesses to communicate individually with their consumers, thereby creating brand presence, and ultimately selling more products is more important. (Wong, 2014). This due to the value of information shared that attract the customers and encourage them to explore more about the product. The customer then will take their own initiative to get to know the product more. To be specific, the same process likely to be happen when government shared valuable information to the public. The curiosity among people will lead them to get to know better about the matters. Plus, the information is come from the government, which is considered to be trusted and reliable sources, there is no doubt to it.

It is mean that the value of information are matters that give impact to the public. Simply, public might take it easy on the information that do not have value on it, and they believe it has nothing to do with them. Still, the value of information is difficult to be determined, but it is indeed giving an impact to the public who received such an information.

\section{Role of Used of Social Media as Medium in Sharing Information to Public}

People are come from different race, sex, ethnicity, religion, socioeconomic status and geographical area. People are living in diversity. In order aspect, people diversity can be described as anything that sets one individual apart from the another. For instance, in term of interests, experience, academic or professional, everyone did have different background on each of the aspects. Diversity has offered people a vast incentive to use social media. In order to find information, they may use social media as a medium flatform. People can learn anything news by using the social media. they can ask a question pertaining to the cloudy matter or asking for advice from the expert using their small fingertips to reach the rest of human population in this earth. It not limited to specific area, region or continent but it covers the whole globe.

An example, a geography teacher can get better understanding about the geography using the social media. he or she can learn about the physical properties of earth surface else well the human society and culture in the any place they want to. He or she can also use the social media to gain better source for teaching and learning process. Narrowing the scope, government and public are interrelated and rely on each other. Government is responsible in governing the organization or the country. To make sure that the governing process run smoothly, the relevant information needs to be reached the public. Government has plenty of ways to reach the public. It is just matter of effectiveness that need to take care of because in time, with the advancement of technology the approach is changing.

Government has to adapt with the changing to reach the target audience. Before the technologies, for the public who live in the rural area, they probably rely on the news from newspaper or the television 
to receive the information. Time changes everything, live condition is improving. They can now be reach using the internet where the usage of internet is not specific for the urban area.

The public role in an organization or in their life are believed to have relationship to the information share by the government agencies that will give impact to their life. Provided, public who have been fine by police because violate driving rule, are waiting for the right chance to pay the fine. The role here is referring to the driver that looking for goods new from the police to reduce the fine and compound payment to the offender. For a businessman or corporation, a news share by the statutory body that governing the companies and business are probably the big issues that will give impact to them. Here, the role are the people who abide under the rule that being govern by the statutory body that governing the companies and business.

\section{Membership Used of Social Media as Medium in Sharing Information to Public}

It is possible to see social media as a positive weapon that revives social conflict. It then supports those people who are having problems with physical social interaction. This can be due to many reasons, one of them is the introvert people. They might have problem in communication verbally due the nervous or full of doubt. Other can be to some restriction to access the gate of opportunity due to the cost and budgeting. Some other might be due to lack of time. The pack and busy daily schedule have obstructed an individual to search and explore the social media. This cannot be denied as people do have other things that is more important and need to put it as a priority first.

Nevertheless, it will not stop them from getting the latest news from the social media. The latest metric found that for social media used to be all about likes and followers (Wong, 2014). It is quite similar to the old school techniques, once people subscribe on magazine subscription, they will get monthly magazine with a lot of offers, discounts and deals.

The method is changing, but the modus operandi is the same with same purposed. In digital trend, it is called as likes, followed, subscribe or any other word depend on the social media application. It treats the user the same as they are membership. They will get a notification of the latest news, no exception unless the user mutes the notification setting. More less, the notification not based on monthly, but it is based on the latest news arise. This can be benefit for government. It will turn the organisation of the government into a social government. The transition would arise from the capacity of social media to allow internal change. (Roengtam, Nurmandi, Almeraz, \& Kholid, 2017).

With the new approach, the membership that public in the government page or web will imprint a positive effect to them. They will get the latest news with the trusted source to rely on even if they do not look for it. Because the news itself will come to the public that follow it in term and form of notification.

\section{Knowledge Sharing UsedofSocial Media as Medium in Sharing Information to Public}

Social networking platform or web-based community that allows individuals within a given limit to create a public, personal or semi-public profile. The profile contains a certain information that can be useful to others, thus the profile can be a bridge to the knowledge about the others. The details will be exchanged with a fluent list of people they choose to share their information with. According to (Khan, Ahmed, Din, \& Amin, 2017), Social networking is a nano-computer-dependent tool that allows users of online communities and networks to build their identities and share knowledge, innovative ideas and photographs or videos. Because of the basic use, the media use fantastic resources as a sharing of information.

In addition, social media is claimed as a perfect forum or source seeking recommendations on goods, music, sports and other items (Wong, 2014). When more and more social media sites continue to highlight images and, for example, to connect to those with buying possibilities. The visual material as a means of " word of mouth" must be assessed by major companies with high expectations and credibility. Lately, social media become famous platform in sharing the information for knowledge 
sharing. There is possibility social networking will become the part of the information distribution by government agencies despite the ubiquitous tools can be used everywhere and reach thousands of people in a second.

Now that the method being adapt by government agencies, the distribution of news will be more effective. The time taken to reach people out there will reduce drastically. The cost incurred will also be reduce. In the perspective from public, they will get to know the latest information with the realtime basis. There is no lag compare to the as at time basis and it can also avoid misunderstanding.

\section{Collaboration \& Interaction Used of Social Media as Medium in Sharing Information to Public}

Since there is less boundary between people, it is easy to create a collaboration and interaction. There is no barrier that going to stop people from interacting with each other. They can communicate freely whenever they want without specific schedule needed.

Social media increase communication, engagement, learning material and related courses that improve productivity by characteristics (Khan, Ahmed, Din, \& Amin, 2017). The communication is loosening, it can be in formal way like in the e-mail as well as informal way like our daily conversation. As a consequence, organisational abilities and information implicitly linked to their work profile and position will be improved. The collaboration is not only on bilateral discussion, it can be trilateral or more. It promoting better discussion and collaboration because it involves different thought and perspective. It provides better understanding and reach neutral agreement in making any decision, if needed.

One of the amazing opportunities when government use the social media is that they can received pretty fast respond and feedback from the public. feedback can be vital part in an organization. Take a closer look, feedback can bring essential information to organization to improve and enhance the activities. Obliquely, it creates a link between two parties and they can rely on each other for better performance on next activities. The feedback affects interaction positively. Constructive feedback is a robust instrument for developing a healthier environment, enhancing efficiency and interaction, and thereby generating better results. This works for many other items, like industry, athletics, schooling and healthcare, not just for the government.

\section{Research Methodology}

The data collected from the quantitative study were distributed to the public in Kuala Lumpur via questionnaires to 150 respondents, since the researchers assume that Kuala Lumpur has a high population density from various population groups. The study aimed to examine the Impact of Government Using Social Media as Medium in Sharing Information to Public. The independent variables (Value, Role, Membership, Knowledge Sharing and Collaboration \& Intention) of this study were used as primary goals of this research, while the dependent variable is Used of Social Media. Statically Package for Social Science (SPSS) were used to analyse the correlation and determining the validity of the hypotheses.

The unit of analysis is the respondents or the target audience that hope to receive the questionnaire are people who live in Kuala Lumpur area with age within 18 years old until 50 years old. Assumption in this research, most probably of the respondent are will be among from middle age which is 25 years old until 50 years old. Via cross-sectional study in the questionnaire, a snapshot of population at the time as this paper study is taken to study the impact, they got from getting information from government agency using social media.

A survey methodology is the technique used in this study. Objective sampling, based on such considerations, is the method of sampling where the chosen sample has words that are deemed to have 
important characteristics that are applicable to the analysis. In survey research, in order to provide a quantitative description of attitudes, opinions and trends, a sample set data of population is studied Cross-sectional or prospective surveys using questionnaires or standardised population interviews for data collection are the ways in which research can be achieved. The goal is to generalise from a specimen to a population. (Muntean, 2015).

\section{Research Framework}

Figure 1 show the research framework that only show the relationship between the use of social media as dependent variable while the independent variable is the role, value, membership, knowledge sharing, collaboration and interaction. The dependent variable results will rely on the independent variable means if there are changes in independent variables, it will be affecting the dependent variable.

Figure 1: Research Framework by the Researcher

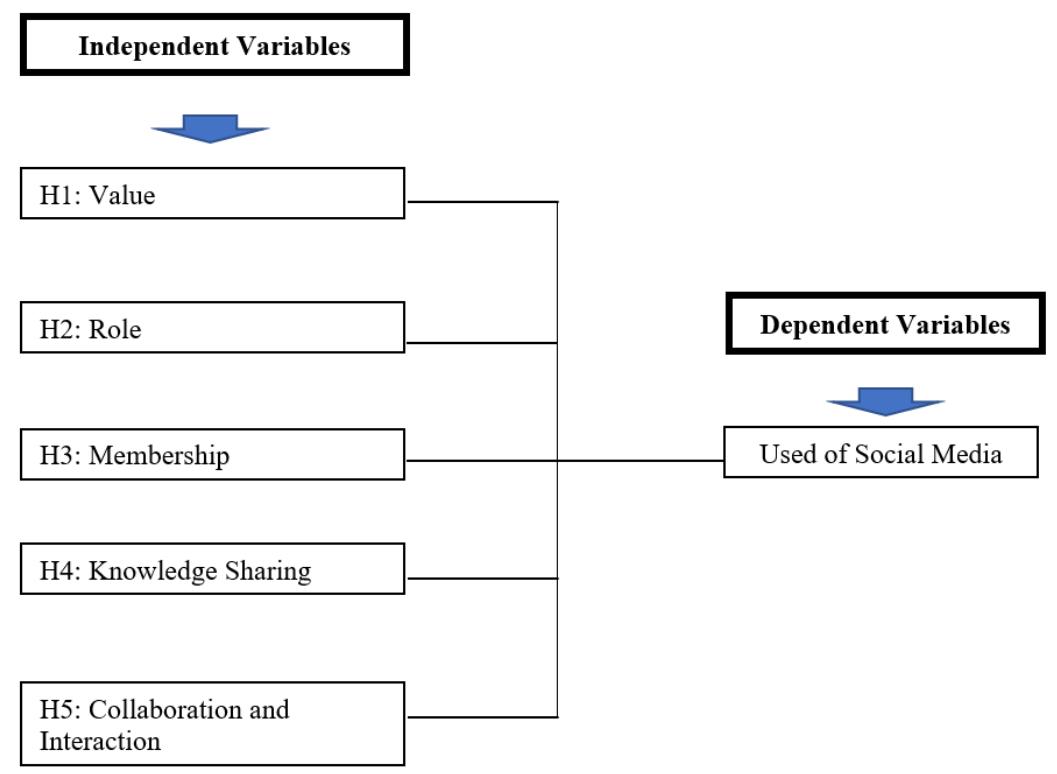

\section{Hypotheses}

The theories are important to keep the path on track in order to get the analysis completely funded and efficient. This study identifies several impacts of using social media to shared information to the public. Hence, below are the list of outcome hypotheses:

H1: There Is Relationship Between Value and Used of Social Media as Medium in Sharing Information to Public.

H2: There Is Relationship Between Role and Used of Social Media as Medium in Sharing Information to Public.

H3: There Is Relationship Between Membership and Used of Social Media as Medium in Sharing Information to Public.

H4: There Is Relationship Between Knowledge Sharing and Used of Social Media as Medium in Sharing Information to Public.

H5: There Is Relationship Between Collaboration \& Interaction Value and Used of Social Media as Medium in Sharing Information to Public. 


\section{Finding Results and Data Analysis}

Regression analysis is used in a situation where an independent variable(s) in one or more metrics is hypothesised to influence a parameter based variable. Regression is used in this analysis to analyse the effects of independent variables. (role, value, membership, knowledge, collaboration and interaction) on used of social media.

\section{Assumption Test}

A few assumption assessments, including multicollinearity, normality, linearity, homoscedasticity and residual independence, have to be examined in order to be reliable and valid for multiple regression analysis. (Tabachnick and Fidell, 2001).

\section{Multicollinearity}

Multicollinearity is a phenomenon in which two or more predictor variables are strongly correlated in a multiple regression model, indicating that one can be estimated linearly with a significant degree of precision from the others. Multicollinearity may be tested in different ways. Multicollinearity was tested in this analysis via the matrix of correlation. When the independent variables are strongly correlated with each other ( $r=0.9$ and above), multicollinearity occurs. In the correlation table below, the independent variables demonstrated some association with other independent variables by providing values of $\mathrm{r}=0.512$ and none above 0.90 . This means that multicollinearity is not demonstrated by the variables.

Table 1: Pearson Correlation

\begin{tabular}{cccccc}
\hline & Role & Value & Membership & $\begin{array}{c}\text { Knowledge } \\
\text { sharing }\end{array}$ & $\begin{array}{c}\text { Collaboration } \\
\text { and } \\
\text { Interaction }\end{array}$ \\
\hline Role & 1 & & & & \\
Value & $0.512^{* *}$ & 1 & & & \\
$\begin{array}{c}\text { Membership } \\
\text { Knowledge sharing }\end{array}$ & $0.695^{* *}$ & $0.736^{* *}$ & 1 & & \\
$\begin{array}{c}\text { Collaboration and } \\
\text { interaction }\end{array}$ & $0.685^{* *}$ & $0.707^{* *}$ & $0.700^{* *}$ & 1 & 1 \\
\hline
\end{tabular}
**. Correlation is significant at the 0.01 level (2-tailed)

\section{Normality}

It is possible to verify normality by looking at a residual histogram. The histogram for residuals in Figure 2 indicates a reasonably normal distribution. Thus, based on these results, the normality of the statement of residuals is satisfied. Assumptions of normality can also be verified by looking at the normal probability map. It indicates that the points lie in a fairly straight diagonal line from bottom left to top right by looking at Figure 3. This shows no noticeable variations from normality. 
Figure 2: Histogram of used of social media

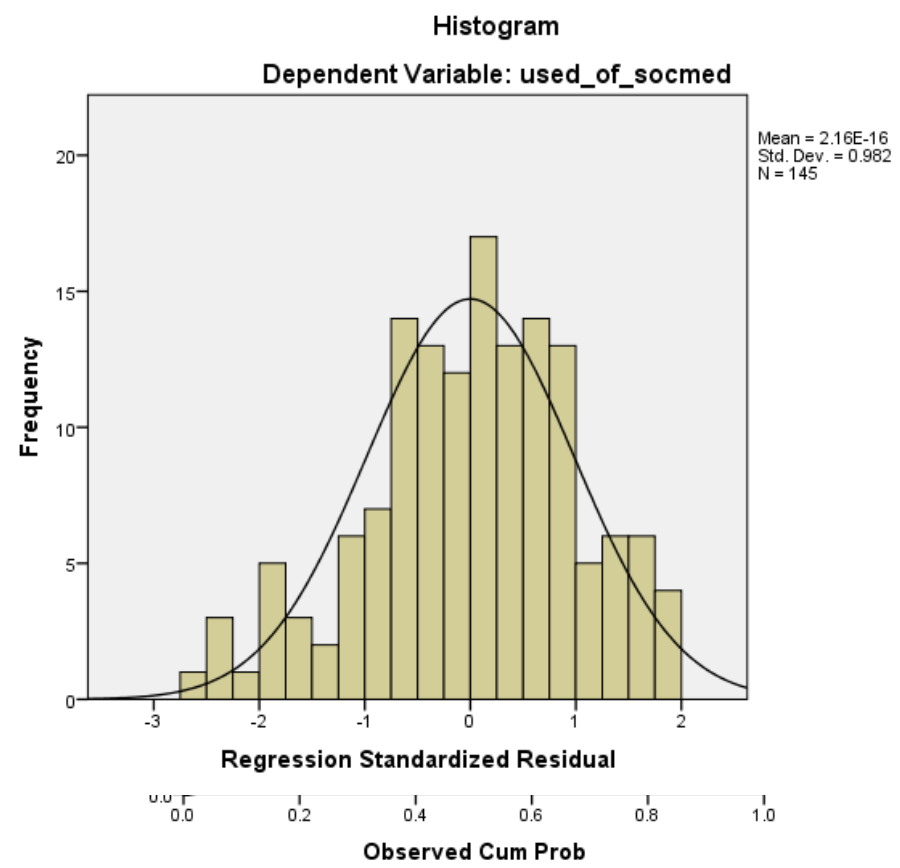

Figure 3: Normal probability plot

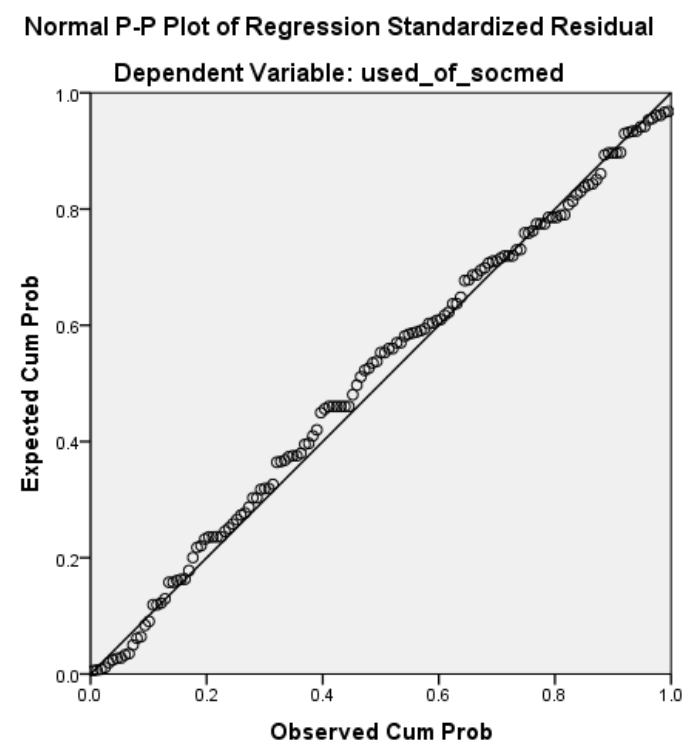

\section{Homoscedasticity}

Homoscedasticity is the assumption that for some point in the model, the variance in the residuals (or volume of error in the model) is identical. In other words, the distribution of the residuals at each stage of the predictor variables should be reasonably stable (or across the linear model). Figure 4 indicates that the residuals are approximately distributed in a rectangular form, with most scores clustered in the centre (along the 0 point). The expectations are not broken by this consequence. 
Figure 1: Scatterplot of the residuals

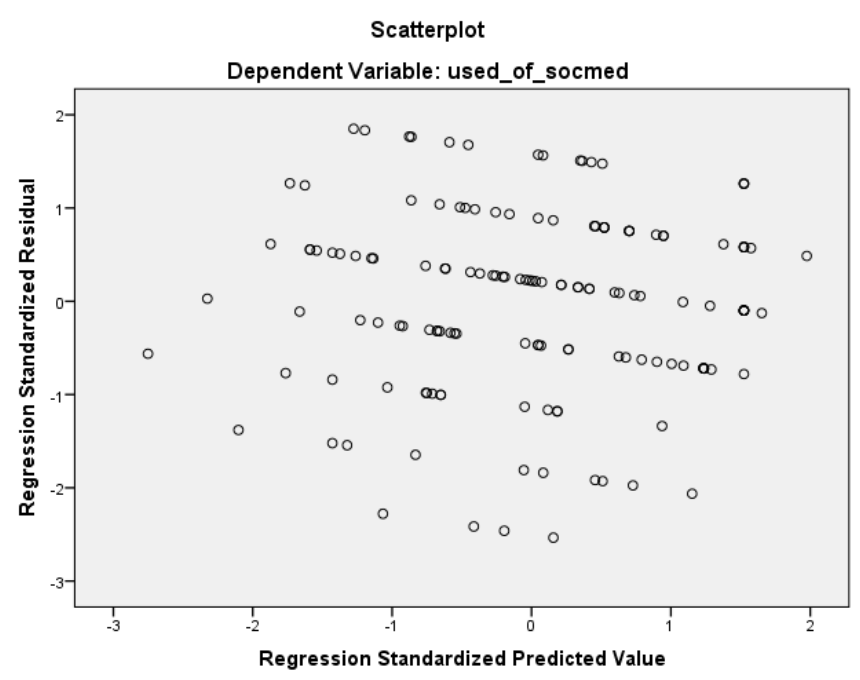

\section{Independent of Residuals}

In order to verify the statement that residuals are independent, Durbin-Watson statistics were used. Values smaller than 1 or greater than 3 are undoubtedly cause for alarm as a very conservative rule of thumb (Field, 2013). The meaning is 1.657 in this case, so we can assume that expectation has been fulfilled.

Table 2: Durbin-Watson statistics

\begin{tabular}{ccccc}
\hline & & \multicolumn{3}{c}{ Std. Error of the } \\
R & R Square & Adjusted R Square & Estimate & Durbin-Watson \\
\hline .209 & .044 & .009 & 1.469 & 1.657 \\
\hline
\end{tabular}

\section{Regression Analysis Result}

From several independent variables, the product of regression is an equation that represents the best estimate of a dependent variable.

Table 3: Regression analysis result

\begin{tabular}{|c|c|c|c|c|c|c|}
\hline \multirow[t]{2}{*}{ Model } & \multicolumn{2}{|c|}{$\begin{array}{c}\text { Unstandardized } \\
\text { Coefficients, } \\
\text { B }\end{array}$} & \multirow{2}{*}{$\begin{array}{c}\text { Standardized } \\
\text { Coefficients, } \\
\text { Beta } \\
\text { Beta } \\
\end{array}$} & \multirow[t]{2}{*}{$\mathrm{t}$} & \multirow[t]{2}{*}{$\mathrm{p}$} & \multirow[t]{2}{*}{$\mathrm{R}^{2}$} \\
\hline & $\mathrm{B}$ & $\begin{array}{c}\text { Standard } \\
\text { error }\end{array}$ & & & & \\
\hline (Constant) & 2.867 & 1.099 & & 2.610 & .010 & \multirow{6}{*}{0.044} \\
\hline Role & .573 & .289 & .249 & 1.979 & $.050 *$ & \\
\hline Value & -.071 & .366 & -.026 & -.193 & .847 & \\
\hline Membership & -.144 & .368 & -.061 & -.391 & .696 & \\
\hline Knowledge & .225 & .359 & .084 & .626 & .532 & \\
\hline Collaboration & -.127 & .298 & -.057 & -.427 & .670 & \\
\hline
\end{tabular}




\section{Hypothesis Testing}

Hypothesis 1: There Is Relationship Between Value and Used of Social Media as Medium in Sharing Information to Public

Regression analysis result shows that there is significant relationship between role and used of social media $($ Beta $=0.249, \mathrm{p}=0.05)$. Therefore, $\mathrm{H} 1$ is rejected.

Hypothesis 2: There Is Relationship Between Role and Used of Social Media as Medium in Sharing Information to Public

Regression analysis result shows that there is no significant relationship between value and used of social media (Beta $=-0.026, \mathrm{p}=0.847$ ). Therefore, $\mathrm{H} 2$ is supported.

\section{Hypothesis 3: There Is Relationship Between Membership and Used of Social Media as Medium in Sharing Information to Public}

Regression analysis result shows that there is no significant relationship between membership and used of social media (Beta $=-0.061, \mathrm{p}=0.696$ ). Therefore, $\mathrm{H} 3$ is supported.

Hypothesis 4: There Is Relationship Between Knowledge Sharing and Used of Social Media as Medium in Sharing Information to Public

Regression analysis result shows that there is no significant relationship between knowledge sharing and used of social media (Beta $=0.084, \mathrm{p}=0.532$ ). Therefore, $\mathrm{H} 4$ is supported.

\section{Hypothesis 5: There Is Relationship Between Collaboration \& Interaction Value and Used of Social Media as Medium in Sharing Information to Public}

Regression analysis result shows that there is no significant relationship between collaboration and interaction and used of social media (Beta $=-0.057, \mathrm{p}=0.670$ ). Therefore, H5 is supported.

Table 4: Summary of hypothesis testing

\begin{tabular}{|c|c|c|c|}
\hline Hypothesis & Hypothesis statement & Result & $\begin{array}{c}\text { Conclusion based on } \\
\text { hypothesis }\end{array}$ \\
\hline $\mathrm{H} 1$ & $\begin{array}{l}\text { There Is Relationship Between Value } \\
\text { and Used of Social Media as Medium in } \\
\text { Sharing Information to Public. }\end{array}$ & $\begin{array}{c}\text { Not } \\
\text { significant }\end{array}$ & Rejected \\
\hline $\mathrm{H} 2$ & $\begin{array}{l}\text { There Is Relationship Between Role and } \\
\text { Used of Social Media as Medium in } \\
\text { Sharing Information to Public. } \\
\text { There Is Relationship Between }\end{array}$ & Significant & Supported \\
\hline $\mathrm{H} 3$ & $\begin{array}{l}\text { Membership and Used of Social Media } \\
\text { as Medium in Sharing Information to } \\
\text { Public. }\end{array}$ & Significant & Supported \\
\hline $\mathrm{H} 4$ & $\begin{array}{l}\text { There Is Relationship Between } \\
\text { Knowledge Sharing and Used of Social } \\
\text { Media as Medium in Sharing } \\
\text { Information to Public. }\end{array}$ & Significant & Supported \\
\hline H5 & $\begin{array}{l}\text { There Is Relationship Between } \\
\text { Collaboration \& Interaction Value and } \\
\text { Used of Social Media as Medium in } \\
\text { Sharing Information to Public }\end{array}$ & Significant & Supported \\
\hline
\end{tabular}




\section{Conclusion}

Based on the research finding, only the role of individual is affected with the information shared by the government agency. The reason is that the target that respond to the questioner are to be found most likely to be civil servant that working related with the agency. They need to know latest rule and regulation on how to run the business and operation to do the work related with them means employee can work better by surfing and searching information independently. The information shared is believed can provide the guideline to the job role. In term of value, the information shared by statutory body are truly demonstrating the industry and the information shared do have respected believed to be valuable in term of accuracy as it is published by the authority. Unfortunately, the content is only focus to increase the awareness on latest rule and regulation with the simple info-graphic information thus cannot bring the raw value of the real content thus did not give an impact to the public.

The membership does not impact public even though the action of subscribing the page are done by people. The reasons are because the notification received from the page are only got a glance of eye. People did not take is serious as they respond to the notification message from their partner or colleague. The natural character of human being to avoid things that don not important have seriously impacting the result as membership did not impacting the public with information shared by government agency. Knowledge sharing through the social media is really can reach thousands of people with cost a dime and occur less than second. It is the faster way to distribute the information in this era. The information goes all over the world across all the boundaries but yet it still cannot increase the level of compliances because that things is depend on the individual whether he or she want to follow the rule and regulation or not. The hypothesis is rejected due no significant relationship between knowledge sharing and used of social media.

For collaboration and interaction, the used of social media by government agency are believed to have better process and efficient working ways to deal with the people demand and complaints. Though it really impacts to the people as it will no longer required to go to the counter and fill the up the form before submit and send to the long queue before being serve.

\section{References}

Ahmed, Y. A., Ahmad, M. N., Ahmad, N., \& Zakaria, N. H. (2019). Social media for knowledgesharing: A systematic literature review. Telematics and Information, 72-112.

Amaral, L. L. (2020). Absentmindedly scrolling through nothing': liveness and compulsory continuous connectedness in social media. Media Culture \& Society, 1-8.

Appel, G., Grewal, L., Hadi, R., \& Stephen, A. T. (2019). The Futue of Social Media in Marketing. Journal of the Academy of Marketing Science, 79-95.

Apuke, O. D. (2017). Quantitative Research Methodes A Synopsis Approach. Arabian Journal of Business and Management Review (Kuwait Chapter), 40-47.

Bernama. (2017, 7 22). SSM Biztrust to Help Prevent Dishonest Online Sellers. Kuala Lumpur, Malaysia: New Straits Time.

Bernama. (2019, 8 13). Cyber Scams Top The List Every Year. Kuala Lumpur, Malaysia: New Straits Time.

Bukhari, S., Hamid, S., Ravana, S. D., \& Ijab, M. T. (2018). Information-Seeking Behaviour Model of International Students' Use of Social Media. Research Gtae - Conference Paper.

Coates, A. E., Hardman, C. A., Halford, J. C., Chritiansen, P., \& Boylland, E. J. (2019, April). Social Media Influencer Marketing and Children's Food Intake: A Randomized Trial. Pediatrics, p. 143(4).

Dekker, R., Engbersen, G., \& Klaver, J. (2018). mart Refugees: How Syrian Asylum Migrants Use Social Media Information in Migration Decision-Making. Social Media + Society.

Dollarhide, M. E. (2020, Sep 6). Social Media Definition. Retrieved from Investopedia: https://www.investopedia.com/terms/s/social-media.asp

Duquesne University. (n.d.). How Health Communicators Use Social Media in Interactive Marketing. Retrieved from Duquesne University - School of Nursing: 
https://onlinenursing.duq.edu/blog/health-communicators-use-social-media-interactivemarketing/

Field. (2013). Discovering Statistic Using IBM SPSS Statistics: And Sex and Drugs and Rock "N" Roll. Los Angelas; London; New Delhi: Sage.

Filippov, S. (2016, 2 7). Government of The Future: How Digital Technology Will Change The Way We Live, Work and Govern. European Digital Forum: Government of The Future. Brussels, Belgium: Digital Insights.

Fuchs, C. (2017). Social Media A Critical introduction. London: SAGE Publicantion Ltd.

Goyal, H. (2020). Social media impact. Academia, 1-62.

Heavenarchive, W. D. (2020, April 7). Why the coronavirus lockdown is making the internet stronger than ever. Retrieved from MIT Technology Review: https://www.technologyreview.com/2020/04/07/998552/why-the-coronavirus-lockdown-ismaking-the-internet-better-than-ever/

Hogan, M. \& Strasburger, V. C. (2018). Social Media and New Technology: A Primer. Research Gate - Clinical Pediatrics.

Khan, M. I., Ahmed, M., Din, S.-u., \& Amin, A. (2017). The Impact of Social Media on Teacher's Performance: A case of Higher Educational Institution of Pakistan. European Online Journal of Natural and Social Sciences, 206-221.

Knowledge Management Tools. (2017). Knowledge Sharing. Retrieved from www.knowledgemanagement-tools.net: https://www.knowledge-management-tools.net/knowledge-sharing.php

Knowledge. Wharton. (2019, July 26). The Impact of Social Media: Is it Irreplaceable? Retrieved from knowledge. wharton.upenn.edu: https://knowledge.wharton.upenn.edu/article/impact-of-socialmedia/

Laal, M., \& Ghodsi, S. M. (2012). Benefits of Collaborative Learning. Social and Behaviour Sciences, 486-490.

McCarthy-Jones, S. (2017, December 8). Are Social Networking Sites Controlling Your Mind? Retrieved from The Conversation: https://www.scientificamerican.com/article/are-socialnetworking-sites-controlling-your-mind/

Muntean, A. (2015). The Impact of Social Media Use of Political Participation.

Nibusinessinfo.co.uk. (n.d.). Nibusinessinfo.co.uk-Home. Retrieved from Nibusinessinfo.co.uk: https://www.nibusinessinfo.co.uk/content/advantages-and-disadvantages-using-social-media

O'keeffe, G. S., Clarke-Pearson, K., \& Media, C. o. (2014). The Impact of Social Media on Children, Adolescent, and Families. Pediatrics Official Journal of the American Academy of Pediatrics.

Ranschaert, E. R. (2015). Social Media in Radiology. European Society of Radiology.

Roengtam, S., Nurmandi, A., Almeraz, D. N., \& Kholid, A. (2017). Does Social Media Trandform City Government? A Case Study of Three ASEAN cITIES. Transforming Government: People, Process and Policy, 343-376.

Schlomer, G.L., Bauman, \& Card, S. \&. (2010). Best Practices for Missing Data Management in Counselling Psychology. Journal of Counselling Psychology, 57(1)9-10.

Shabbir, M. S., Ghazi, M. S., \& Mehmood, A. R. (2016). A Impact of Social Media Application on Small Business Entrepreneurs. Arabian Journal of Business and Management Review.

Shaharudin, Z. M. (2018). Useage of Social Media for Higher Education. Research Hub.

Shearer, E. (2018, 12 10). Pew Research Center - Fact Tank. Retrieved from Pew Research Center: https://www.pewresearch.org/fact-tank/2018/12/10/social-media-outpaces-print-newspapers-inthe-u-s-as-a-news-source/

SimpliLearn. (2020, Nov 13). Understanding The Impacts of Social Media: Pros and Cons. Retrieved from impliLearn: https://www.simplilearn.com/real-impact-social-media-article

Tabachnick, \& Fidell, B. \&. (2007). Using Multivariate Statistic (5th Edition). Boston: Allyn and Bacon.

Taber, \& Keith. (2017). The Use of Cronbachá Alpha when Developing and Reporting Research Instrument in Science Education. Research in Science Education, 1-24.

Treem, J. W., Dailey, S. L., Pierce, C. S., \& Biffl, D. (2016). What we are talking about when we talk about social media: a framework for study. Sociology Compass, 7768-784.

Tursunbayeva, A., Franco, M., \& Pagliari, C. (2017). Use of Social Media for e-Government in the Public Sector: A Systematic Review of Published Studies. Goverment Information Quarterly $34,270-282$. 
DOI: https://doi.org/10.47405/mjssh.v6i3.711

UNAL, S. (2018). The Effect of Social Media Use to The Time Spent with Family Members. International Journal of Eurasia Social Science, 550-578.

Wani, P. H., \& Sarodw, D. N. (2017). Social Media and Its Impact on The Users. International Journal of Trend Scientific Research and Development, 931-934.

Winship, C., \& Mandel, M. (n.d.). Roles and Positions: A Critique and Extension of the Blockmodelling Approach. Socialogical Methodology, 314-344.

Wolf, M., Sims, J., \& Yang, H. (n.d.). Social Media? What Social Media?

Wong, K. (2014, 5 13). What is The Value of Social Media Engagement? Retrieved from Forbes.com: https://www.forbes.com/sites/kylewong/2014/05/13/what-is-the-value-of-social-mediaengagement/\#e3555925951d 